\title{
El vitalhumanismo
}

\author{
Miguel Ángel Polo Santillán \\ Universidad Nacional Mayor de San marcos \\ mpolos@unmsm.edu.pe
}

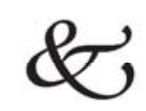

\section{Introducción}

Darío Botero Uribe (1938-2010) ${ }^{1}$ fue profesor emérito de la Universidad de Colombia, cuenta con una vasta producción filosófica, unida por un proyecto original denominado Vitalismo Cósmico. Entre sus obras podemos mencionar: La voluntad de poder de Nietzsche (1992, con cuatro ediciones), Teoría social del derecho (1993, con cuatro ediciones), Manifiesto del pensamiento latinoamericano (1993, con cinco ediciones), El derecho a la utopía (1994, con cinco ediciones), Vida, ética y democracia (1995, con dos ediciones ${ }^{2}$ ), Vitalismo Cósmico (2002), Discurso sobre el humanismo (2004), entre otros. Un rasgo de su actividad filosófica ha sido lograr constituir una escuela filosófica, que pretende mirar críticamente las filosofías actuales para poder formular una nueva propuesta, el Vitalismo Cósmico, desde el contexto latinoamericano. En este artículo queremos presentar sus principales tesis de la siguiente manera: la visión del hombre, la propuesta humanista y la ética vitalista que de ahí se genera. Finalmente, reflexionar sobre algunos aspectos problemáticos de su humanismo.

\section{La humanidad como transnaturaleza}

La principal tesis es que el hombre es tanto naturaleza como transnaturaleza $^{3}$. Lo que podríamos llamar biología y cultura, unidad indisoluble. Sin embargo, es la transnaturaleza lo que hace a la humanidad como tal, es decir, la cultura, la historia, las creencias, los ideales, el espíritu, todo mediado por el lenguaje. Y la clave que une ambas dimensiones es el lenguaje. Dice el filósofo: "Lo humano no es un carácter conquistado por el hombre de una vez por to-

1 Conocí al maestro Darío Botero el año 2005, en el 1er. Encuentro Nacional por la Vida, que él organizó en Bogotá. Sin duda, él era expresión de su propia filosofía vitalista.

2 Los datos sobre el número de ediciones han sido tomados del artículo de Damián Pachón (2008).

3 Idea sostenida principalmente en Discurso sobre el humanismo (2004) y en Vitalismo cósmico (2002). "La naturaleza y la transnaturaleza se articulan en el hombre de una manera profunda y necesaria. Puede pensarse que forman una unidad en el hombre: el hombre es natural y transnatural.” (2002, p.215)

LETRAS 81 (116), 2010 
das, sino la dimensión transnatural que entra a configurar el animal cultural. Lo humano comienza a construirse a partir del lenguaje" (2004, p. 198). La transnaturaleza se expresa a través de la cultura, la sociabilidad, la producción y la creación (2002, p. 215). Por eso el humanismo de Botero apuesta por abrir las puertas a la transnaturaleza, entendida como creación, pensamiento, pasión de vivir, es decir, un humanismo con una filosofía de la vida.

Junto con esta tesis aparece otra referida al lenguaje: "El lenguaje hace del hombre una animal universal" (2004, p. 198). O, como más adelante afirma, "El lenguaje fue decisivo para humanizar al hombre: lo sacó de la particularidad de la naturaleza y lo arrojó a la universalidad de su ser humano" (2004, p. 210). La naturaleza es el ámbito de la particularidad, mientras el lenguaje lo arroja a la universalidad y la potencialidad. Tenemos entonces:

"La transnaturaleza no es una continuidad de la naturaleza sino una ruptura, la más profunda que se haya hecho a Gaia: un animal brotado de su seno salió de su soberanía y sin dejar de ser naturaleza, diseñó un proyecto propio y proclamó una soberanía alternativa y complementaria de la naturaleza." (2004, p. 211)

La propuesta del vitalismo cósmico es una apuesta por construir un "puente de doble vía" entre naturaleza y transnaturaleza, con la finalidad de "restablecer" la armonía. Y, claro está, que este proyecto es transnatural, no puede venir espontáneamente de la naturaleza sino de los seres humanos.

Otra de sus tesis es que el hombre es una unidad tensional de razón y norazón. Más adelante entiende por no-razón (que no lo identifica con irracionalidad) lo siguiente:

"La no-razón es una apelación al pensamiento y a la conducta inconscientes del individuo que tienen base pulsional; base que de ninguna manera se agota en la sexualidad sino que determina la forma típica del talento, de la creatividad, de la inteligencia, de la lúdica..." (2004, p. 217)

La propuesta vitalista abarca y articula la razón como la dimensión eróticoafectiva. Por lo anterior, el vitalismo cósmico considera que el hombre puede darse a sí mismo su propio ser:

"El hombre es biológicamente un ser de la naturaleza que debido a superposición de su ser transnatural, prácticamente no ha vuelto a evolucionar; pero su ser transnatural es programable en alguna escala en el ámbito social y en la esfera individual, con las ambiciones, las necesidades, la esperanza, la planeación, las luchas, los esfuerzos...” (2004, p. 199)

Como lo había sostenido anteriormente es, el hombre no se logra de una vez y para siempre, sino "El hombre está siempre humanizándose o deshuma- 
nizándose" (2002, p. 285). La humanidad tiene la tarea de "reinventarse" cada día a través del lenguaje, la cultura y la ética, por eso se hacen importantes los humanismos.

\section{Humanismo transnaturalista}

Desde estos presupuestos, se puede deducir que el humanismo tiene su fuente en la transnaturaleza, no en la dimensión biológica (que a veces llama antropológica) sino en la dimensión psicosociocultural. Botero hace la distinción entre un humanismo antropológico y un humanismo transnatural. Por eso sostiene que el "humanismo no se basa en la antropología sino en la transnaturaleza" (2002, p. 285). Siguiendo las líneas críticas de Foucault a la antropología, afirma: "La antropología como fundamento del humanismo tiene tres limitantes: 1) depende de la naturaleza; 2) es caracterizada por la esencia; 3) es ahistórica" (2002, p. 287). Entendido en esos términos la antropología, por eso no asume que su filosofía de la vida se sostenga en una antropología, sino en la transnaturaleza. Así, el filósofo colombiano quiere fundamentar el humanismo en la transnaturaleza:

"Yo, por mi parte, no fundamento el humanismo en la antropología sino en la transnaturaleza. De esta manera resulta que la caracterización, 1) no se hace con base en la naturaleza, sino en la transnaturaleza; 2) no se apoya en la esencia sino en la persistibilidad; 3) no es un movimiento único transhistórico sino un conjunto de movimientos humanistas históricos, que obedecen a causales propias de cada época." (2002, p. 288)

Como hemos visto, si bien el hombre es tanto natural como transnatural, el humanismo como valoración de lo humano es proyección de la transnaturaleza, porque es un "proyecto del hombre, alternativo al programa de la naturaleza y concurrente con él” (2004, p. 209). Por lo que afirma:

"Lo excepcional del hombre no es la biología sino su desarrollo mental, intelectual, cultural. Lo que tipifica la humanidad del hombre no es la naturaleza sino lo que él mismo ha creado históricamente a partir del desarrollo de la mente, del pensamiento, del entendimiento, de la razón. El humanismo es, pues, un desarrollo histórico de la humanización" (2004, p. 199)

La transnaturaleza no incluye pues una visión esencialista, en lugar de ello el autor quiere hablar de "persistibilidad", es decir, "permanencia en el cambio" (2004, p.199). Persistir en pensar, en ser, en hablar y hasta en la propia autodestrucción. Por lo que se hace indispensable el humanismo:

"El humanismo es necesario porque la amenaza de deshumanización persiste siempre; en cada época con distintos proyectos, desde distintas 
perspectivas es necesario humanizar. La humanización no es algo que hayamos asegurado definitivamente. Cada ser humano y cada proceso social, político, cultural humaniza o deshumaniza." (2004, p. 200)

Ante la persistente deshumanización contrapone una persistente "pluralidad de humanismos"4 que defienda la dignidad humana. La visión no esencialista ${ }^{5}$ hace que no asuma la dignidad humana como una cualidad o característica de los hombres, sino que la asuma como una atribución que nos hacemos para respetar y humanizar.

"La dignidad como carácter intrínseco no es una verdad empírica, pero como atribución normativa puede llegar a ser una verdad cultural, en la medida en que pudiera contribuir a crear un orden de respeto al hombre y de humanización de la vida social.” (2004, p. 200)

Darío Botero ve en esta atribución de dignidad una manera de fundamentar los derechos humanos. El autor rechaza la creencia que la dignidad es una esencia transhistórica, pero tampoco cree que esa atribución de valor sea arbitraria. Así, desde una perspectiva histórica, "lo humano mismo se modifica en la medida en que en cada época adquiere un sentido nuevo, unos valores y unas connotaciones especiales" (2004, p. 201). Podríamos decir que las personas sienten como necesario el atribuirse dignidad para defenderse de posibles actos que atenten contra su integridad. Así:

"La atribución de dignidad no es algo gratuito, caprichoso sino una interpretación humanista respecto a lo humano: lo humano es la dimensión transnatural del hombre; en virtud de ello el humanismo interpreta lo humano como merecedor de dignidad." (2004, p. 201)

Sin embargo, parece ser que la dignidad también es extendida a la naturaleza, distanciándose del planteamiento kantiano. "La naturaleza es un fin en sí misma”, afirma Botero. Las acciones y producciones humanas no deben dañar el orden de la vida, deben estar en función de la autogeneración de la vida. Con ello tampoco propone el filósofo colombiano una subordinación a la naturaleza, sino una sana interacción hombre-naturaleza, basada en la continuidad de la vida. Por lo que afirma:

"La producción y en general la interacción hombre-naturaleza tiene que partir de una premisa fundamental: el respeto a los derechos de la vida. Esto se puede lograr de varias maneras: dejando que la vida fructifique

4 En una obra anterior, sostenía sobre esta pluralidad de humanismos: "No existe un humanismo sino muchos humanismos ligados a distintas causas de defensa del hombre. La persistencia de estos se debe a que la humanización es siempre precaria y debe volver a renovarse siempre." (2002, p.287).

5 Más adelante afirma: "Uno de los problemas de los humanismos del pasado es precisamente que devenían naturalismos esencialistas; jugaban a una naturaleza singular más allá o más acá de la universalidad naturaleza. Ese camino está cerrado para la lucidez, pues conduce a un callejón sin salida." (2004, p.209). 
y tomando los frutos; integrando el proceso de vida a la producción, lo cual significa que la producción se fomenta técnicamente en beneficio del hombre sin dañar la naturaleza; produciendo en interacción con la naturaleza, pero delimitando filosófica y científicamente los límites de la acción humana...De todas maneras defender los ecosistemas tiene que ser una política audaz y consistente. El balance entre naturaleza mediada por el hombre y la naturaleza no hollada tiene que mantenerse o el desequilibrio de la vida será irreversible.” (2004, p. 205)

El vitalhumanismo de Botero relaciona la vida humana con la vida, desde ahí replantea la concepción de la naturaleza. Apartándose del proyecto moderno occidental señala que la naturaleza no es una cosa al servicio del hombre, sino que "la naturaleza es la continuidad de la vida en la cual está inmerso el hombre" (2004, p. 212). Así pues, la naturaleza toda (la vida humana y la vida) es un fin en sí mismo. Y una vez más precisa:

"Esto solo significa que hoy hemos comprendido que no podemos entorpecer la fluidez de la vida. Esto no significa que no podamos tomar un bocado de vida, que no podamos actuar tecnológicamente en la naturaleza, sino que no podemos perturbar impunemente los ecosistemas sin dañar irremediablemente la circulación de la vida.” (2004, p. 213)

El vitalismo cósmico de Botero trabaja con un concepto amplio de vida, entendida como vida cósmica, vida biológica y vida psicosocial. Todas estas formas que toma la vida tiene una característica: la inmanencia o flujo que se retroalimenta: "la vida es una corriente circular que se retroalimenta en los productos de la vida; todo lo que ha pertenecido a la vida regresa a la vida. Mientras no alteremos radicalmente la fluidez de la corriente de la vida, la vida seguirá su curso ininterrumpido" (2004, p. 215). Pero esto tiene al final un sentido materialista: con la muerte física nuestros elementos materiales vuelven al ciclo vital, mientras nuestros productos psicosociales permanecen en la sociedad humana. Y con ello afirma que para el vitalismo cósmico no existe la muerte.

Como señalamos, busca construir un puente entre naturaleza y transnaturaleza que restablezca la armonía, para que el nomos no destruya la physis. En esa dirección señala:

"El Vitalhumanismo no aísla al hombre de la historia, de la cultura, del desarrollo social, pero tampoco de la naturaleza; se trata de un humanismo en torno a la vida que conduce a buscar el hilo de la vida humana en la vida; es un humanismo que no abstrae al hombre sino que lo proyecta a encontrar el sentido y la ubicación de la vida. No se puede defender la vida humana sin defender la vida; de ahí la profunda solidaridad del hombre con el orden universal de la vida.” (2004, p. 214) 
Así, el hombre no tiene privilegio entre los seres vivos y como todos ellos requiere sumergirse en la vida pero permitiendo que ella continúe ${ }^{6}$. No tiene privilegio natural, pero su carácter especial viene de la transnaturaleza. Por eso escribe:

"El hombre no es biológicamente el centro del universo; pero desde el punto de vista estratégico, como testigo lúcido, desde la proyección de su inteligencia y su conocimiento; de la ambición artística, científica y filosófica sí es el centro, a menos que se descubra en el cosmos otro ser que pueda competir con él." (2004, p. 215)

\section{Ética vitalista}

Botero tiene muchas entradas para abordar el tema ético: el poder desmesurado, el individuo, la universalidad, la barbarie, etc. Entiende por ética "la autorregulación de ese poder desmesurado" (2004, p. 215), necesaria -además del derecho- para la configuración de la socialidad. La libertad presupone un orden, condicionamientos que la hacen posible. La libertad se expresa en los proyectos de vida:

"La consciencia que implica el proyecto de vida nos amplía la perspectiva de pensamiento, creación y acción en un campo específico de la no-razón (talento y fuerza pulsional), el que hemos escogido para realizarnos humanamente." (2004, p. 216)

Ese individuo debe hacer posible la compatibilidad entre la universidad vida y la universalidad transnaturaleza, más aún, el filósofo colombiano entiende que el individuo representa tanto el polo de la singularidad como el de la universalidad (2004, p. 216). "El diálogo entre los dos -añade- constituye la autoeducación y funda la eticidad de que es capaz cada individuo...el individuo puede acceder consciente y responsablemente a la universalidad" (2004, p. 216$)^{7}$. La apuesta de la ética vitalista es entonces por los individuos, por la

6 Otra forma de presentar la importancia del concepto "vida" en el humanismo es la siguiente: "la vida es una energía dinámica, autopoyética, creadora de formas, que busca satisfacción, pugna por persistir en su ser. La disputa por la razón y la ordenación económica agotan la modernidad; la vida insurge como fundamento de una nueva cultura. Con el concepto de vida la razón se desplaza de su hegemonía y, en cambio, surge el paradigma razón, no-razón: la vida en tanto orden pulsional es no-razón, pero en tanto proyección a la acción social es razón. Este nuevo paradigma representa un equilibrio que armoniza la razón con la no-razón.” (2002, p. 292)

7 En Vitalismo Cósmico lo plantea así: "Pienso que individuo y hombre no obstante que caracterizan a un mismo y único ente no son muy armoniosos. Individuo y hombre marcan una contradicción fuente de energía creadora, de potencialidad, pero también de egoísmo destructor, de barbarie. La educación y la cultura deben lograr un equilibrio entre las tendencias universales e individuales." (2002, p. 290). 
"producción de individuos", pero individuos universales. El sentido paradójico hace que haya una interdependencia entre individuo y universalidad. ${ }^{8}$

Junto con el individuo está la apuesta por el valor de la vida, la vida como valor central. Pero, como ya advertimos, no para entenderla como propiedad natural de un ente llamado naturaleza, sino como flujo autopoyético. Una vez más aclara:

"Si la vida se alimenta de vida en todas las escalas de la naturaleza, la vida come vida y genera vida. No es el consumo de la vida lo que destruye la vida; no es propiamente la acción depredadora la que destruye la vida; es más bien la interferencia abusiva del proceso de circulación de la vida lo que mata la vida." (2004, p. 216)

Hay que pensar que esta autorregulación ética atiende tanto a las dimensiones de la razón y la no-razón. Por eso su distanciamiento de las éticas de origen kantiano. Así: "Una ética basada en el paradigma razón, no-razón implica un equilibrio entre la universalidad naturaleza y la universalidad transnaturaleza" (2004, p. 217).

¿Cómo entender esa ética del individuo que se autorregula? El filósofo anota con suma claridad:

"Un individuo es autoconsciente, tiene la autoconsciencia que ha necesitado para formarse como individuo. Para plantear la libertad tiene necesidad de autorregular su conducta: la ética es un autodominio o autogobierno de su vida. No consiste en autodefinirse arbitrariamente sino en regular el espacio y el sentido de su autonomía frente a los otros; esto implica necesariamente una apelación a la razón, es decir, a la universalidad transnaturaleza (social, cultural, política, etc.) y a la universalidad naturaleza (el entorno de la vida que debe ser protegido); pero todo esto se hace desde el yo inconsciente y pulsional, de la personalidad concreta del individuo, de la no-razón; por tanto la ética es una tensión y un diálogo entre esos dos momentos, entre razón y no-razón." (2004, p. 217)

El objetivo de la ética vitalista sin duda es defender la vida (en sus tres dimensiones: cósmica, biológica y social), eso es bueno, lo contrario es malo (2004, p. 218). Eso implica liberar a la naturaleza del "poder perturbador y opresivo". Devolver al hombre a la vida, sacarlo de su encierro autodestructivo:

"Si la vida es sólo humana y todas las demás especies y formas de vida le son dadas para su disfrute, la vida en la perspectiva de hoy ya no es viable. Tenemos que devolver el hombre a la naturaleza, sumergirlo en la Vida para que con una nueva conciencia pueda organizar entonces

8 Por eso señala con respecto a lo individual y lo universal: "la contradicción primordial que yo planteo, que no se supera nunca. La ética en mi concepción consiste en un equilibrio entre lo individual y lo universal, lo egoísta y lo social, lo corporal y lo espiritual en cada persona." (2002, p. 221).

LETRAS 81 (116), 2010 
Miguel Ángel Polo Santillán

desde la transnaturaleza el intercambio de vida por vida en una forma

regulativa, no destructiva." (2004, p. 218)

Una vez más, busca un camino medio entre el idealismo de considerar sagrada a la naturaleza y la destrucción de la naturaleza. En ambos casos el hombre se coloca fuera de la naturaleza, cuando lo que existe son "corrientes de vida", en las que se expresan "ecosistemas, nichos, formas alimentarias, hábitos, intercambios, etc.” (2004, p. 219). El autor cree ver en este concepto "corrientes de vida" una mejor forma de interpretar y fundar programas para evitar las destrucciones ambientales.

Finalmente, de esa interdependencia entre naturaleza-transnaturaleza deriva la idea de una sociedad sana, necesaria para una naturaleza sana. "La vida natural es el reflejo de la vida social: el orden de la interacción social es el orden de la interactividad vida humana-vida natural; el caos social, la miseria, la violencia es destrucción de la vida en ambas orillas” (2004, p. 219). Y la apuesta política del vitalismo cósmico de Botero es por la democracia radical ${ }^{9}$. Una democracia que genere igualdad, armonía en la vida transnatural puede generar una armonía con la vida natural.

\section{Observaciones}

1. La visión del ser humano, para no hablar de antropología, busca una armonía de opuestos. No reduccionismo, tampoco separación que aísla. El hombre es esa contradicción, paradójica, trágica armonía de opuestos: individuo-sociedad, egoísta-universal, cuerpo-pensamiento, natural-transnatural y racional-no-racional. No hay principio que las unifique, salvo el principio vida.

2. Justamente que ese concepto eje, central en su filosofía, es el centro del problema: ¿qué es? Si bien caracteriza a la vida por procesos como la naturalidad, inmanencia, transmisibilidad, autopoyesis, diversidad, autonomía, etc., ¿puede ella establecerse como principio, casi al modo presocrático? La filosofía de la vida es un canto a la libertad creadora del individuo, pero no desde una metafísica sino desde una visión naturalista y social de la vida.

3. Botero habla de tres formas como se expresa la vida: cósmica, biológica y psico-social. Como sabemos, su teoría se llama "vitalismo cósmico", apostando por la vida cósmica como clave interpretativa ${ }^{10}$. Sin embargo, esto

9 El tema de la democracia es tratado en Vida, ética y democracia (2001).

10 Como sostiene el filósofo colombiano, Damián Pachón, el concepto de "vida cósmica" es el más problemático en Botero (2008). La explicación de la vida como energía cósmica roza mucho con una metafísica materialista, fuente de toda su visión trágica. Sus fuentes son tanto biólogos como filósofos. 
puede tener dos significados: a) referirse al cosmos como realidad física, lo que implicaría aceptar la existencia de la vida en otros mundos, posibilidad no negada por la ciencia; b) por vida cósmica podría referirse a la capacidad de las transnaturaleza humana de universalizarse, es decir, que las creaciones humanas puedan elevarse a rango de universalidad y darle sentido cósmico al todo, a ese frío universo en el que nos encontramos. Al parecer Botero apostaría por la segunda versión. Si además, la vida es autopoyesis, flujo circular, se puede entender que en la muerte el cuerpo material regrese a la materia, ¿y la transnaturaleza? Parece que Botero piensa en las grandes creaciones humanas que regresan a la cultura ${ }^{11}$, ¿pero qué sucede con las experiencias personales cotidianas? ¿también regresa eso? Parece que Botero prefiere no hablar de ello porque eso sería pensar en un karma humano, una acumulación de experiencias que dejamos para las siguientes generaciones. Eso supondría una vida realmente transnatural y transhumana, pero la vida transnatural de Botero solo es humana, no llega a ser transhumana.

4. Subyace en su propuesta cosmovitalista un materialismo vitalista, que no da paso (aunque pudiera darlo) a una visión espiritualista. Su sentido de espíritu solo alcanza la historia y las producciones humanas, pero un vacío con respecto a una vida espiritual que trascienda los límites humanos. Su propuesta se acerca más a Epicuro y Nietzsche que a Spinoza, autor que aprecia, aunque éste último pensador divinizaba la naturaleza y naturalizaba la divinidad, paso que no es dado por Botero, prefiriendo la visión trágica de la vida, sin unidad trascendente o divina que la resuelva. Una filosofía de la vida que no es un canto a la naturaleza, sino a la vida humana y sus mejores producciones, teniendo como principio ético la responsabilidad ante la vida.

5. No encontramos en su obra, quizá falta de información nuestra, que haga una valoración de las formas tradicionales de proteger la vida, del cuidado de los ecosistemas, del respeto y unión con la naturaleza. Su soporte teórico es más filosófico que basado en las tradiciones ancestrales, por eso quizá su poca apertura al valor de las religiones en la postura vitalista.

6. Frente a la acción depredadora de la vida, destrucción de la naturaleza, el autor propone la autorregulación. ¿No es esto solo parte de la solución? En su propuesta ética, la autorregulación es un proceso racional y no-racional, por lo que habría que pensar que ese poder avasallador sería también tanto racional como no-racional. ¿Qué los diferenciaría entonces?

11 Dice Botero: "lo que muere entonces son las células envejecidas...pero el espíritu como lenguaje, como creación, como reflexión, como deseo, vive y pervive en los demás y la materia orgánica también sigue su camino vivificando" (2001, p.20). Más adelante añade: "Sólo quien ha vivido con pasión, la transformación es generosa; instala al muerto en la conciencia de los sobrevivientes, le asegura una vida larga, una invocación permanente.” (2001, p. 22)

LETRAS 81 (116), 2010 
Pues el primero permite que la vida fluya, mientras el segundo altera la corriente de la vida. La autorregulación entonces tendrá que completarse con la política. Una vez más se abre paso a la acción estatal que controla las pasiones humanas.

7. Creo que en esta perspectiva es más preciso hablar de "derecho a que la vida persista”, porque la expresión "derecho a la vida” en general podría llevar al fundamentalismo, posición que el mismo autor quiere evitar. Lo que propone Botero es que la acción humana no perjudique el flujo de la vida, por lo tanto regulación y autorregulación (no solo no destruir el medio ambiente sino también más educación y cultura). La expresión “derecho a la vida”, por ser ambigua, implica consecuencias que el vitalismo de Botero no aceptaría, como el vegetarianismo. El ser humano tendría que discernir qué y cómo se pueden consumir los seres no humanos para que la vida fluya.

8. Finalmente encontramos en Botero un espíritu que reclamaba Nietzsche, un sentido vitalista, trágico, sostenido por una ciencia feliz, una gaya ciencia, un saber que exalte la dimensión no racional de la vida -sin dejar de ser racionales- y abra espacios de reconciliación con nosotros mismos ${ }^{12}$.

\section{Referencias bibliográficas}

BOTERO URIBE, Darío (2001). Vida, ética y democracia. Bogotá, Universidad Nacional de Colombia. BOTERO URIBE, Darío (2002). Vitalismo cósmico. Bogotá, Universidad Nacional de Colombia. BOTERO URIBE, Darío. (2004) Discurso sobre el humanismo. Bogotá, Ecoe Ediciones.

PACHÓN, Damián. (2008). "Una mirada crítica al vitalismo cósmico de Darío Botero Uribe", en http://filosofiacolombiana.blogspot.com/2008_10_01_archive.html

12 "Sólo quien ama la vida -sostiene Botero- puede prepararse para transmutarse con una sonrisa, con una mueca, con un rictus de desdén.” (2001, p. 21). 